\title{
Practical Aspects of Broken Rotor Bars Detection in PWM Voltage-Source-Inverter-Fed Squirrel-Cage Induction Motors
}

\author{
Hong-yu Zhu, ${ }^{1,2,3,4}$ Jing-tao Hu, ${ }^{1,2,3}$ Lei Gao, ${ }^{1,2,3}$ and Hao Huang ${ }^{1,3}$ \\ ${ }^{1}$ Shenyang Institute of Automation, Chinese Academy of Sciences, Shenyang 110016, China \\ ${ }^{2}$ University of Chinese Academy of Sciences, Beijing 100049, China \\ ${ }^{3}$ Key laboratory of Industrial Information Technology, Chinese Academy of Sciences, Shenyang 110016, China \\ ${ }^{4}$ School of Electronic and Information Engineering, University of Science and Technology Liaoning, Anshan 114044, China
}

Correspondence should be addressed to Hong-yu Zhu; zhuhongyu@sia.cn

Received 5 June 2013; Revised 18 September 2013; Accepted 23 October 2013

Academic Editor: Xianxia Zhang

Copyright (C) 2013 Hong-yu Zhu et al. This is an open access article distributed under the Creative Commons Attribution License, which permits unrestricted use, distribution, and reproduction in any medium, provided the original work is properly cited.

\begin{abstract}
Broken rotor bars fault detection in inverter-fed squirrel cage induction motors is still as difficult as the dynamics introduced by the control system or the dynamically changing excitation (stator) frequency. This paper introduces a novel fault diagnosis techniques using motor current signature analysis (MCSA) to solve the problems. Switching function concept and frequency modulation theory are firstly used to model fault current signal. The competency of the amplitude of the sideband components at frequencies $(1 \pm 2 s) f_{s}$ as indices for broken bars recognition is subsequently studied in the controlled motor via openloop constant voltage/frequency control method. The proposed techniques are composed of five modules of anti-aliasing signal acquisition, optimal-slip-estimation based on torque-speed characteristic curve of squirrel cage motor with different load types, fault characteristic frequency determination, nonparametric spectrum estimation, and fault identification for achieving MCSA efficiently. Experimental and simulation results obtained on $3 \mathrm{~kW}$ three-phase squirrel-cage induction motors show that the model and the proposed techniques are effective and accurate.
\end{abstract}

\section{Introduction}

Squirrel-cage induction motors have dominated the field of electromechanical energy conversion. They consume more than $60 \%$ of the electrical energy produced and are present in the main industrial applications $[1,2]$. Although still considered proverbially robust, all components of induction machines are subject to increased stress, particularly when operated in a controlled mode and with repeated load cycles [3]. According to studies, broken rotor bars and cracked end-ring faults in the rotor cage are responsible for about $5-10 \%$ of all breakdowns and incipient detection of these events remains a key issue $[4,5]$. The main reason why early detection is important is that although broken rotor bars may not cause immediate failure, there can be serious secondary effects associated with their presence [6,7]. If faults are undetected, they may lead to potentially catastrophic failures. Thus, health-monitoring techniques to prevent the induction motor failures are of great concern in the industry and are gaining an increasing attention.
Motor current signature analysis (MCSA) has been successfully applied to detect broken-rotor bar faults by investigating the sideband components around the supplied current fundamental frequency (i.e., the line frequency) $f$

$$
f_{b}=(1 \pm 2 s) f
$$

where $f_{b}$ are the sideband frequencies associated with the broken rotor bars and $s$ is the per unit motor slip $[4,8,9]$. Some quantitative conclusion based on the left sideband values (LSB) of the amplitude-frequency spectrum plot of a motor phase current even recommends $-50 \mathrm{~dB} \sim-35 \mathrm{~dB}$ of the sideband harmonics as the threshold level for generating a warning or alarm [10]. In addition, MCSA has been tested in many industrial cases since the 1980s with good results [1116].

Even though numerous successful main-fed motor fault detection methods are reported in the literature, bibliography relative to inverter-fed motors on this topic seems to be poor. With the increased emphasis on energy conservation and 
lower cost, induction machines are supplied and controlled by inverters, and the use of inverter drives increases day by day. As a result, dynamic performance is excellent due to all kinds of control methods and the next steps in drive development are going to be driven by attempts to increase reliability and reduce maintenance costs. By using the current sensor feedback and microprocessing unit, the new tread for low-cost protection applications seems to be drive-integrated fault diagnosis systems without using any external hardware. Thus, it becomes more demanding to detect faults by using MCSA in these drives.

The introduction of voltage-source-inverter-fed (VSIfed) motors has produced significant changes in the field of diagnosis and control, needing further research in order to overcome various challenges. Contrary to the motor line current taken directly from the main, the inverter-fed motor line current includes remarkable noise (inherent floor noise which reduces the possibility of true fault pattern recognition using line current spectrum) due to the high-frequency switching devices, EMI and EMC effects, and so forth. The current signal for rotor fault diagnosis needs precise and high resolution information, which means the diagnosis system demands additional hardware such as a low-pass filter, highprecision AD converter, and additional software. Moreover, closed-loop control in IM drives introduces new difficulties in broken rotor bar detection, as traditional fault indicators tend to be masked by a control algorithm. Therefore, the methods developed for an open-loop operation are not able to produce adequate and reliable information on the extent of the fault and have to be adapted $[4,17,18]$. All these influences complicate the utilization of frequency analysis methods. VSI-fed motor faults have been analyzed, and the initial results are given in the literature but further investigation is still required.

The classic MCSA method works well under constant load torque and with high-power motors, and it has mainly been designed for fixed frequency supply, such as for machines connected to the electrical grid. To obtain satisfactory test results, in [7], recommendations are given from the author's experience. As stated in this paper, literally, "the load on the motor should be sufficiently high to produce at least $35 \%$ of rated full load rotor slip for a reliable single-test broken bar analysis." and "if the motor to be tested is fed from a variable-speed converter drive, the frequency of the drive should be locked at the $50 / 60 \mathrm{~Hz}$ power supply frequency for the test." Yet, difficulties emerge when inverted-fed motors are applied to drive fans, pumps, or other mechanisms involving speed control for energy-saving purpose. In these cases, the excitation frequency will truly depend on the speed reference and the load applied to the system. Therefore, unlike the utility-driven case, the stator excitation frequency will dynamically change and the position of the current harmonics appearing on the stator-current spectrum due to electrical faults is highly dependent on the mechanical motor load and excitation frequency, which affects the slip frequency. As a consequence, the conventional MCSA must be amended to accommodate the new scenarios. Unfortunately, to the best of our knowledge, in the published literatures there is no research work on this subject.

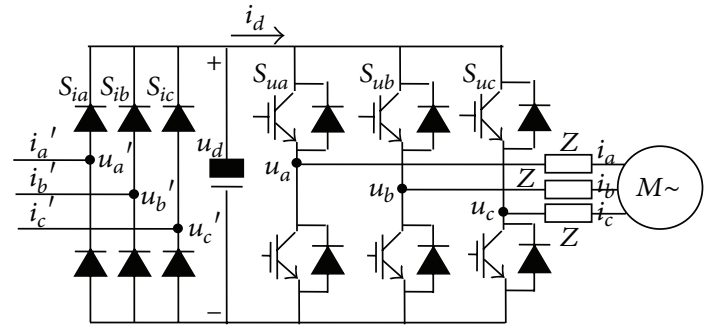

FIGURE 1: Schematic diagram of the PWM VSI-fed adjustable speed drive.

In this context, following explicitly derivation from a simplified fault signal model, a new online fault diagnosis technique based on MCSA for inverter-fed squirrel-cage induction motors is present. Compared with traditional MCSA, the novelty of the proposed method is that broken rotor bars fault in the controlled motor via open-loop constant voltage/frequency control method could be identified even if the motor operates at different excitation frequencies. To do this, oversampling signal acquisition technique is used to suppress significantly noise contained in the invertedfed motor line current, and fault-indicative frequencies with variable excitation frequency are determined by torque-speed characteristic curve of squirrel-cage motor with different load types. To obtain satisfactory results, nonparametric spectrum estimation algorithm and fault identification are subsequently presented. Including this introductory section, this paper is organized into six sections. Section 2 presents a theoretical analysis model of stator current of inverter-fed squirrel-cage motor, which is based on switching function concept and modulation theory. A detailed description of the harmonic components contained in current is given. Section 3 elaborates the new broken rotor bars fault diagnosis techniques. In Section 5, the proposed techniques are validated by laboratory tests; the method is applied to different stator currents obtained from healthy and faulty machines. Experimental and simulation results as well as the corresponding analysis and discussion are presented in Section 4. Finally, conclusions and recommendations are presented in the last section.

\section{Analytic Model of Stator Current Signature for Squirrel-Cage Induction Motor with Constant Volt-per-Hertz Control Technique}

2.1. Analytic Model of Stator Current Signature for No-Fault Squirrel-Cage Induction Motor. Switching function concept is a powerful tool in understanding and optimizing the performance of the converter $[19,20]$. In [20], an analytical approach for characterizing the current harmonics and interharmonics of the VSI-fed ASD injected into the supply system in steady is presented using the switching function concept, applicable to PWM VSI that is studied in this paper. Figure 1 shows the schematic diagram of a typical PWM VSI-fed adjustable speed drive, where $S_{i a}, S_{i b}$, and $S_{i c}$ represent the rectifier converter current switching functions that correlate 
the three-phase AC source currents $i_{a}^{\prime}$, $i_{b}^{\prime}$, and $i_{c}^{\prime}$ and the inverter input DC current $i_{d}, S_{u a}, S_{u b}$, and $S_{u c}$ represent the inverter voltage switching functions that correlate inverter $\mathrm{dc}$ input voltage and output phase voltages $u_{a}, u_{b}$ and $u_{c}, Z$ is the impedance operator seen from the inverter output terminals corresponding to the neutral point of induction motor. In order to calculate and analyse the harmonic currents generated by the VSI-fed ASD, an analytical model based on the modulation theory and switching function concept is proposed and expressed by (2) (6). After obtaining the phase currents of PWM VSI-fed motor, the harmonic components of the current might be extracted by the use of a certain spectrum analysis method as follows:

$$
\begin{gathered}
\left(i_{a}^{\prime}, i_{b}^{\prime}, i_{c}^{\prime}\right)=i_{d}\left(S_{i a}, S_{i b}, S_{i c}\right), \\
i_{d}=\left(i_{a}, i_{b}, i_{c}\right)\left(S_{u a}, S_{u b}, S_{u c}\right)^{\prime}, \\
u_{d}=\left(u_{a}^{\prime}, u_{b}^{\prime}, u_{c}^{\prime}\right)\left(S_{i a}, S_{i b}, S_{i c}\right)^{\prime}, \\
\left(u_{a}, u_{b}, u_{c}\right)=u_{d}\left(S_{u a}, S_{u b}, S_{u c}\right), \\
\left(i_{a}, i_{b}, i_{c}\right)=\frac{\left(u_{a}, u_{b}, u_{c}\right)}{Z} .
\end{gathered}
$$

As shown in Figure 1, for the two-level natural sampled PWM with a triangular wave of carrier signal, the three-phase voltage switching functions $S_{u a}, S_{u b}$ and $S_{u c}$ can be expressed as the following double Fourier series, as follows:

$$
\begin{aligned}
S_{u a}(t)= & \frac{M}{2} \sin \left(\omega_{s} t\right)+\frac{2}{\pi} \sum_{m=1}^{\infty} J_{0}\left(\frac{m M \pi}{2}\right) \\
& \cdot \sin \left(\frac{m \pi}{2}\right) \cdot \sin \left(m \omega_{c} t\right) \\
& +\frac{2}{\pi} \sum_{m=1}^{\infty} \sum_{n= \pm 1}^{\infty} \frac{J_{n}(m M \pi / 2)}{m} \sin \left[\frac{(m+n) \pi}{2}\right] \\
& \times \sin \left(m \omega_{c} t+n \omega_{s} t\right), \\
S_{u b}(t)= & \frac{M}{2} \sin \left(\omega_{s} t-\frac{2 \pi}{3}\right)+\frac{2}{\pi} \sum_{m=1}^{\infty} J_{0}\left(\frac{m M \pi}{2}\right) \\
& \cdot \sin \left(\frac{m \pi}{2}\right) \cdot \sin \left(m \omega_{c} t\right) \\
& +\frac{2}{\pi} \sum_{m=1}^{\infty} \sum_{n= \pm 1}^{\infty} \frac{J_{n}(m M \pi / 2)}{m} \sin \left[\frac{(m+n) \pi}{2}\right] \\
& \times \sin \left[m \omega_{c} t+n\left(\omega_{s} t-\frac{2 \pi}{3}\right)\right], \\
S_{u c}(t)= & \frac{M}{2} \sin \left(\omega_{s} t+\frac{2 \pi}{3}\right)+\frac{2}{\pi} \sum_{m=1}^{\infty} J_{0}\left(\frac{m M \pi}{2}\right) \\
& \cdot \sin \left(\frac{m \pi}{2}\right) \cdot \sin \left(m \omega_{c} t\right)
\end{aligned}
$$

$$
\begin{aligned}
& +\frac{2}{\pi} \sum_{m=1}^{\infty} \sum_{n= \pm 1}^{\infty} \frac{J_{n}(m M \pi / 2)}{m} \sin \left[\frac{(m+n) \pi}{2}\right] \\
& \times \sin \left[m \omega_{c} t+n\left(\omega_{s} t+\frac{2 \pi}{3}\right)\right] .
\end{aligned}
$$

For a hypothetical ideal motor supplied from a balanced three-phase source of sinusoidal voltages and driving a constant load, the following waveform of selected phase-a stator current may be assumed by substituting (7) into (5) and (6), where the commutation effect is ignored and proper origin of coordination selected for convenience of analysis is as follows:

$$
\begin{aligned}
i_{a}= & \frac{M E_{d}}{2\left|Z\left(\omega_{s}\right)\right|} \cos \left[\omega_{s} t-\varphi\left(Z\left(\omega_{s}\right)\right)\right] \\
& +\frac{2 E_{d}}{\pi\left|Z\left(m N \omega_{s}\right)\right|} \sum_{m=1}^{\infty} J_{0}\left(\frac{m M \pi}{2}\right) \sin \left(\frac{m \pi}{2}\right) \\
& \times \cos \left[m N \omega_{s} t-\varphi\left(Z\left(m N \omega_{s}\right)\right)\right] \\
& +\frac{2 E_{d}}{\pi\left|Z\left((m N+n) \omega_{s}\right)\right|} \sum_{m=1}^{\infty} \sum_{n= \pm 1}^{ \pm \infty} \frac{J_{n}(m M \pi / 2)}{m} \\
& . \sin \left[\frac{(m+n) \pi}{2}\right] \cdot \cos \left[(m N+n) \omega_{s} t\right. \\
= & I_{1} \cos \left(\omega_{s} t-\varphi_{1}\right)+I_{2} \sum_{m=1}^{\infty} J_{0}\left(\frac{m M \pi}{2}\right) \sin \left(\frac{m \pi}{2}\right) \\
& \times \cos \left(m N \omega_{s} t-\varphi_{2}\right) \\
& +I_{3} \sum_{m=1}^{\infty} \sum_{n= \pm 1}^{ \pm \infty} \frac{J_{n}(m M \pi / 2)}{m} \cdot \sin \left[\frac{(m+n) \pi}{2}\right] \\
& \times \cos \left[(m N+n) \omega_{s} t-\varphi_{3}\right],
\end{aligned}
$$

where $M$ is amplitude modulation index, $M=U_{s} / U_{c} \leq 1 ; \omega_{s}$ is frequency of the modulation waveform (reference) $(\mathrm{rad} / \mathrm{s})$, $\omega_{s}=2 \pi f_{s} ; \omega_{c}$ is frequency of the carrier signal $(\mathrm{rad} / \mathrm{s}) ; N$ ratio of the carrier frequency to the modulation frequency, $N=\omega_{c} / \omega_{s} \geq 1$; and $J_{0}, J_{n}$ are Bessel functions of the first kind with order 0 and order $n$, respectively.

\subsection{Analytic Model of Stator Current Signature for Faulty} Squirrel-Cage Induction Motor. When broken rotor bar or cracked end-ring faults develop in the rotor cage, the current, torque, and speed of the motor are affected, typically, in a periodic manner. In the case of periodic disturbances, all three line currents $i_{a}, i_{b}$, and $i_{c}$ are simultaneously modulated with the fundamental frequency $f_{o}$ of the fault-induced oscillation of motor variables. If only amplitude modulation and fundamental frequency $f_{o}$ are considered, current in phase-a of the supply line may now be expressed as

$$
i_{f}=i_{a}\left[1+a \cos \left(\omega_{o} t\right)\right],
$$


where $a$ denotes the modulation depth (modulation index) and $\omega_{o}=2 \pi f_{o}=2 s \omega_{s}=4 \pi s f_{s}$. The value of the modulation index depends on the severity of the abnormality and motor loads.

Substituting (8) in (9) yields

$$
\begin{aligned}
& i_{f}=I_{1} \cos \left(2 \pi f_{s} t-\varphi_{1}\right)+I_{2} \sum_{m=1}^{\infty} J_{0}\left(\frac{m M \pi}{2}\right) \sin \left(\frac{m \pi}{2}\right) \\
& \times \cos \left(2 \pi m N f_{s} t-\varphi_{2}\right) \\
& +I_{3} \sum_{m=1}^{\infty} \sum_{n= \pm 1}^{ \pm \infty} \frac{J_{n}(m M \pi / 2)}{m} \cdot \sin \left[\frac{(m+n) \pi}{2}\right] \\
& \times \cos \left[2 \pi(m N+n) f_{s} t-\varphi_{3}\right] \\
& +a I_{1}\left\{\cos \left[2 \pi(1+2 s) f_{s} t-\varphi_{1}\right]\right. \\
& \left.+\cos \left[2 \pi(1-2 s) f_{s} t-\varphi_{1}\right]\right\} \\
& +a I_{2} \sum_{m=1}^{\infty} J_{0}\left(\frac{m M \pi}{2}\right) \cdot \sin \left(\frac{m \pi}{2}\right) \\
& \cdot\left\{\cos \left[2 \pi(m N+2 s) f_{s} t-\varphi_{2}\right]\right. \\
& \left.+\cos \left[2 \pi(m N-2 s) f_{s} t-\varphi_{3}\right]\right\} \\
& +a I_{3} \sum_{m=1}^{\infty} \sum_{n= \pm 1}^{ \pm \infty} \frac{J_{n}(m M \pi / 2)}{m} \cdot \sin \left[\frac{(m+n) \pi}{2}\right] \\
& \cdot\left\{\cos \left[2 \pi(m N+n+2 s) f_{s} t-\varphi_{3}\right]\right. \\
& \left.+\cos \left[2 \pi(m N+n-2 s) f_{s} t-\varphi_{3}\right]\right\},
\end{aligned}
$$

indicating that the spectrum of stator current for inverter-fed healthy squirrel-cage motor contains, apart from the fundamental $f_{s}$ equal to the inverter excitation (stator) frequency, $m N f_{s}$ harmonics at the carrier frequency and multiples of the carrier frequency and $(M m+n) f_{s}$ harmonics in the sidebands around each multiple of the carrier frequency. When a bar breaks, a rotor asymmetry occurs. The result is that it induces in the stator current additional frequency at $f_{b}=(1 \pm 2 s) f_{s}$, $f_{b 1}=(m N \pm 2 s) f_{s}$, and $f_{b 2}=(m N+n \pm 2 s) f_{s}$ around harmonics frequency depicted above. The amplitude of faultindicative frequencies $f_{b}=(1 \pm 2 s) f_{s}, f_{b 1}=(m N \pm 2 s) f_{s}$, and $f_{b 2}=(m N+n \pm 2 s) f_{s}$ depends on faulty severity, loads and excitation (stator) frequency, and the distance between $f_{b}, f_{b 1}$, and $f_{b 2}$ and corresponding harmonics frequency $f_{s}$, $m N f s,(M m+n) f_{s}$ is equal to $2 s f_{s}$. The amplitude of $f_{b 1}$ and $f_{b 2}$ can be considered negligible compared to that of $f_{b}$; as a result, $f_{b}=(1 \pm 2 s) f_{s}$ are adopted as fault-indicative frequencies.

In practice, the current is modulated with respect to not only the amplitude but also the phase, and the modulation process is more complex than that described by (9), but the derived equation (10) provides an adequate basis for qualitative assessment of diagnostic media.

\section{Diagnosis Techniques of Broken Rotor Bars for Squirrel-Cage Induction Motor with Constant Voltage/Frequency Control Method}

3.1. Principles of Diagnosis. A motor diagnosis technique, which contains the five processing modules illustrated in Figure 2, is presented, based on model of squirrel-cage induction motor stator current signature depicted in Section 2. The current flowing in single phase of the induction motor is sensed by anti-aliasing signal acquisition module and sent to spectrum estimation module, where the obtained time-domain signal can be decomposed into components of different frequency using Welch's periodogram method. In optimal-slip-estimation module, based on the real speed, the inverter excitation frequency, and torque-speed characteristic curve of squirrel-cage motor with different load types, the motor slip is calculated and the consequent optimal slip estimation value is transmitted to fault characteristic frequency determination module, where characteristic frequencies of broken rotor bars are calculated. Depending on whether the characteristic frequencies of $f_{b}=(1 \pm 2 s) f_{s}$ could be found in power spectrum obtained in spectrum estimation module, the conclusion of failure or not could be drawn, this work is done in fault identification module.

3.2. Method of Antialiasing Signal Acquisition. When carrying out diagnostic analysis one of the key elements to obtain good results is to properly choose acquisition parameters: the sampling frequency and the number of samples. There are two different constraints: analysis signal bandwidth and frequency resolution for the spectrum analysis.

It must be considered, when capturing the stator current signal, that the sampling frequency $f_{\text {sample }}$ plays an important role. Generally, statistical bands of fault-indicative frequencies can be ascertained from theory analysis and many MCSA experiments $[2,8,21-23]$. Table 1 summarizes the range of sideband frequencies in terms of faulty types. We see in Table 1 that the spectral analysis of stator currents might be done in low frequency range (typically between 0 and $2 \mathrm{kHz}$ ) to focus on the significant phenomena [24], and in the case of broken rotor bars fault, the fault-indicative frequencies are under $400 \mathrm{~Hz}$. Thus, taking into account the Nyquist criterion, a very high sampling frequency value is not mandatory in case that the motors are supplied by the ac grid. Sampling frequencies of $2 \mathrm{k}$ or $5 \mathrm{k}$ samples/s (standard in data acquisition devices) enable good resolution analysis.

In contrast, for the inverter-fed motors, sampling procedure is more demanding. As it is known, stator current contains high-order frequency harmonics, in this case, due to switching frequencies in modern inverter, typically above $10 \mathrm{kHz}$. Thus, aliasing may occur due to wrong sampling. Antialiasing techniques have to be used in order to have a correct current spectrum and prevent a false failure alert.

For decreasing alias to an acceptable level, it is common to design a sharp-cutoff low-pass anti-aliasing filter and sample the signal at a frequency lower than the dominant frequency components such as the fundamental and the switching 


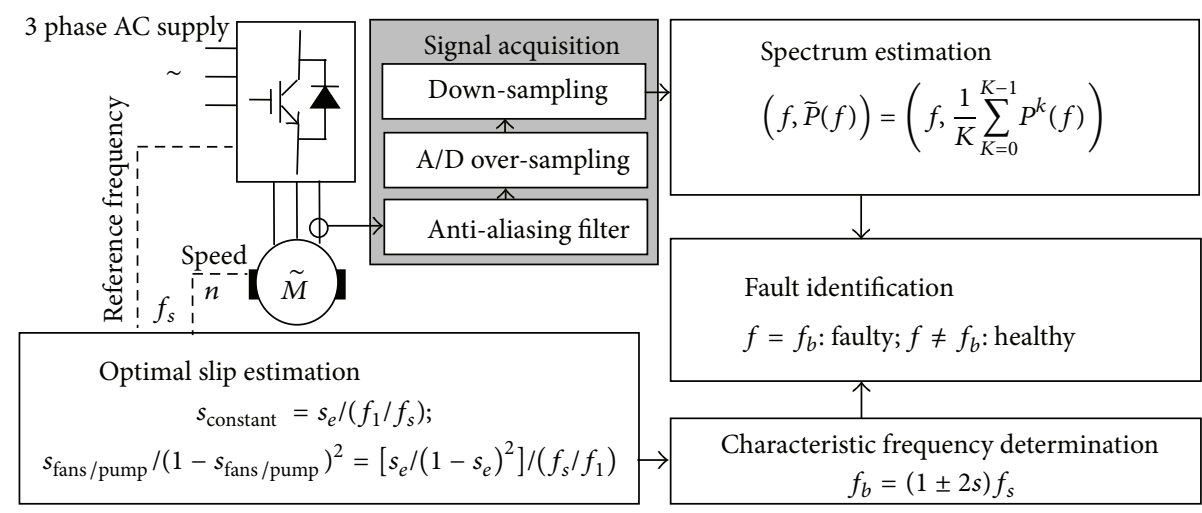

FIGURE 2: Schematic diagram of fault diagnosis.

TABLE 1: Range of sideband frequencies in terms of faulty types.

\begin{tabular}{|c|c|c|c|}
\hline Fault types & Theoretical formula & Range & Frequencies \\
\hline Air-gap eccentricity & $f_{\mathrm{ecc}}=f_{s}\left[1 \pm m\left(\frac{1-s}{p}\right)\right]$ & Low, high & $0 \sim 900 \mathrm{~Hz}$ \\
\hline Broken rotor bars & $f_{b}=f_{s}\left[k\left(\frac{1-s}{p}\right) \pm s\right]$ & Low & $0 \sim 400 \mathrm{~Hz}$ \\
\hline Bearing failure & $f_{i, o}=\frac{n_{b}}{2} f_{r}\left[1 \pm \frac{b_{d}}{p_{d}} \cos \beta\right]$ & High & $0 \sim 2000 \mathrm{~Hz}$ \\
\hline Interturn short circuit & $f_{\text {stl }}=f_{s}\left[\frac{m}{p}(1-s) \pm k\right], \quad f_{\text {sth }}=f_{s}\left[1 \pm m Z_{2}\left(\frac{1-s}{p}\right)\right]$ & Low, high & $0 \sim 1000 \mathrm{~Hz}$ \\
\hline
\end{tabular}

frequencies [25]. However, such sharp-cutoff analog filters are difficult and expensive to implement, and if the system is to operate with a variable sampling rate, adjustable filters would be required. Furthermore, sharp-cutoff analog filters generally have a highly nonlinear phase response, particularly at the pass-band edge. In our proposed method, oversampling as an alternative technique is used. The principle of oversampling is briefly reviewed as follows (see [26] for details). A very simple anti-aliasing filter that has a gradual cutoff with significant attenuation is firstly applied to prefilter the motor stator phase-a current. Next, implement the A/D conversion at a higher sampling rate. After that, downsampling the obtained signal with a lower sampling frequency is implemented using a digital low-pass filter.

As for the inverter supply, several harmonics could be mixed up in case that low resolution of the band side was chosen. In general, one can take the following steps to select data acquisition parameters in order to achieve the correct resolution needed.

(1) Definition of sampling frequency. For anti-aliasing purpose, $f_{\text {sample }}$ has limitation as $f_{\text {sample }} \geqslant 2 f_{c}$, where $f_{c}$ is the highest fault-indicative frequency.

(2) Selection of required frequency resolution $\Delta f$.

(3) Specification of the number of samples $N=$ $f_{\text {sample }} / \Delta f$.

(4) Determination of sampling time $T=N / f_{\text {sample }}=$ $N T_{s}$.
3.3. Calculation of Slip and Fault-Indicative Frequencies with Variable Excitation Frequency. From Section 2, broken rotor bars can be detected by monitoring the stator current spectral components $f_{b}=(1 \pm 2 s) f_{s}$, where harmonic frequencies $f_{b}$ are a function of slip $s$ and excitation frequency $f_{s}$. In case of broken rotor bars fault, excitation frequency $f_{s}$ and the corresponding slip $s$ must be firstly determined in order to find harmonic frequencies $f_{b}$. The result of a motor diagnosis using MCSA is incorrect if the detected slip has an error $[8,27]$. One of the most popular ways to obtain the information of the slip frequency is to use speed sensor. In our proposed method, slip $s$ is calculated in optimal-slip-estimation module, based on the real measured speed and torque-speed characteristic curve of squirrel-cage motor.

The torque-speed characteristic curve of different load types is shown in Figure 3. Curves (1), (2) and (3) are inherent characteristic curves of squirrel-cage motor corresponding to different excitation frequency $f_{s}$. For ease of analysis, it is assumed that torque characteristic curves (1), (2) and (3) intersect mechanical characteristic curve $f_{1}$ at nominal operating point $A$ and only excitation frequency $f_{s}<f_{1}$ is considered (if $f_{s}>f_{1}$, motor operates at point $A_{3}$ of curve (3)). In Figure 3 , the value of slip $s$ corresponding to point $A$ is $s_{e}=\left(n_{01}-n_{e}\right) / n_{01}$. The no-load speedes corresponding to different excitation frequency can be expressed as $n_{01}=$ $60 f_{1} / p$ and $n_{02}=60 f_{s} / p$, where $p$ denotes the number of pole-pairs. 


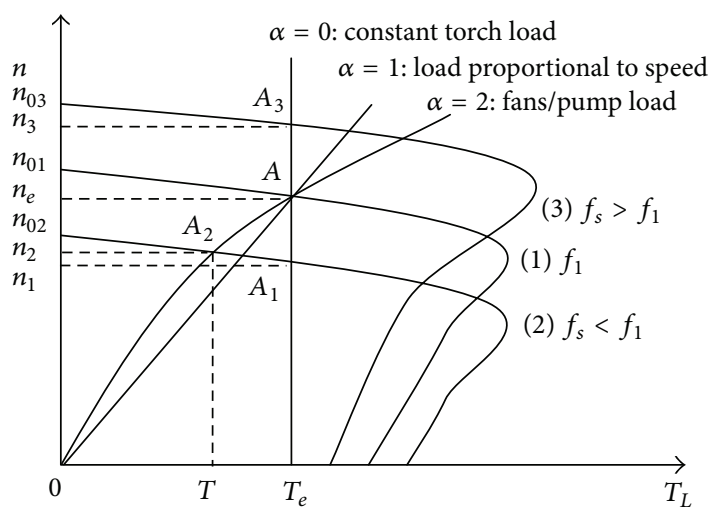

FIGURE 3: Torque-speed characteristic curve of squirrel-cage motor with different load types.

If motor works with constant torque load, the operate point shifts from $A$ to $A_{1}$, the slip $s$ corresponding to $A_{1}$ is equal to $s_{\text {constant }}=\left(n_{02}-n_{1}\right) / n_{02}$. Considering the congruent relationship between $\Delta n_{01} n_{e} A$ and $\Delta n_{02} n_{1} A_{1}$, we can deduce the specific slip formula as follows: $s_{\text {constant }}=s_{e} /\left(f_{1} / f_{s}\right)$.

If motor works with fans/pump load, the operating point shifts from $A$ to $A_{2}$ and the slip $s$ corresponding to $A_{2}$ is equal to $s_{\text {fans/pump }}=\left(n_{02}-n_{2}\right) / n_{02}$. Considering the similarity of $\Delta n_{01} n_{e} A$ to $\Delta n_{02} n_{1} A_{1}$ and relationship of $T / T_{e}=\left(n_{2} / n_{e}\right)^{2}$ between speed and torque of fans/pump, we can deduce the specific slip formula as follows: $s_{\text {fans/pump }} /\left(1-s_{\text {fans } / \text { pump }}\right)^{2}=$ $\left[s_{e} /\left(1-s_{e}\right)^{2}\right] /\left(f_{s} / f_{1}\right)$.

3.4. Nonparametric Spectrum Estimation Algorithms. MCSA techniques include parametric and nonparametric spectrum analysis of the motor current in general [28]. Among the nonparametric algorithms, we use Welch's periodogram algorithms based on DFT to compute the power spectrum of the phase-a motor current data.

Let $i_{N}[n]=\{i[0], i[1], \ldots, i[N-1]\}$ be a discrete time signal, which is obtained by sampling the phase-a motor current signal $i(t)$ for a duration of sampling time $T$. To reduce the variance of power spectrum estimate, the $N$ point data sequence, $i_{N}[n]=\{i[0], i[1], \ldots, i[N-1]\}$, is first partitioned into $K$ overlapping segments. The length of each segment consists of $L$ samples and these segments can be overlapping on each other with $(L-S)$ overlapping samples, where $S$ is the number of points to shift between segments. Thereafter, the periodogram of each segment is calculated and the obtained periodograms are then averaged to give the power spectrum estimate.

The length of segment $L$ is dependent on the required resolution. In order to increase the quality of power spectrum estimates, the signal segments can be windowed before calculating FFT. The proposed methods permit reduce the variance of the estimate at the expense of a decreased frequency resolution. However, it is difficult to trade off between the frequency resolution and the estimate variance. It has been noted that the use of $50 \%$ overlapping percentage among the partitioned segments leads to efficient implementation of the fast Fourier transform (FFT) algorithm and in this case the relationship between $K$ and $L$ of segment as follows $K=$ $(N-L / 2) /(L / 2)$.

Algorithm 1.

Step 1. Subdividing $N$-point sampled data sequence, $i_{N}[n]=$ $\{i[0], i[1], \ldots i[N-1]\}$, into $K$ overlapping segments; the $k$ th segment data $x[n+k S], 0 \leqslant n \leqslant L-1$ and $0 \leqslant k \leqslant K-1$, is as follows:

$$
\begin{aligned}
& \text { Segment 1: } x[0], x[1], \ldots, x[L-1] ; \\
& \text { Segment 1: } x[S], x[S+1], \ldots, x[L+S-1] ;
\end{aligned}
$$

Segment $K: x[N-L], x[N-L+1], \ldots, x[N-1]$.

Step 2. Weighting $k$ th segment, $d[n]$ denote rectangular window function:

$$
x^{k}[n]=d[n] x[n+k S], \quad 0 \leqslant n \leqslant L-1,0 \leqslant k \leqslant K-1 .
$$

Step 3. Calculating power spectrum of the $k$ th segment data:

$$
P^{k}(f)=\frac{1}{\mathrm{ULT}} X(f)[X(f)]^{*}=\frac{1}{\mathrm{ULT}}|X(f)|^{2},
$$

where $X(f)=T \sum_{n=0}^{L-1} x^{(k)}[n] e^{-j 2 \pi f n T}$ denote DFT of the $k$ th segment data and $U=T \sum_{n=0}^{L-1} d^{2}[n]$ denote normalization factor.

Step 4. Averaging all segments power spectrum:

$$
\widetilde{P}(f)=\frac{1}{K} \sum_{k=0}^{K-1} P^{k}(f) .
$$

\section{Experiment Setup and Signal Acquisition Methods}

4.1. Experiment Setup. Schematic diagram of the experiment setup is shown in Figure 4. This system can be used to sample line current $i_{a}$ and line voltage $u_{a b}$ (if necessary, it can be arranged to sample the other line currents $i_{b}$ and $i_{c}$ and line voltages $u_{b c}$ and $u_{c a}$, too), and speed signals. The main components of the experiment setup are as follows.

(1) Three-phase $3 \mathrm{~kW}$ SCIM (see Table 2 for details).

(2) Digital stroboscope coupled with the shaft of the SCIM as angular-speed sensor to measure and record the time variation of the speed.

(3) DC generator coupled with the SCIM to provide its adjustable load.

(4) Mechanical coupling between SCIM and dc generator.

(5) Variable resistor bank as a variable load of the generator: the load of the generator and, consequently, the induction motor can be adjusted by varying this 


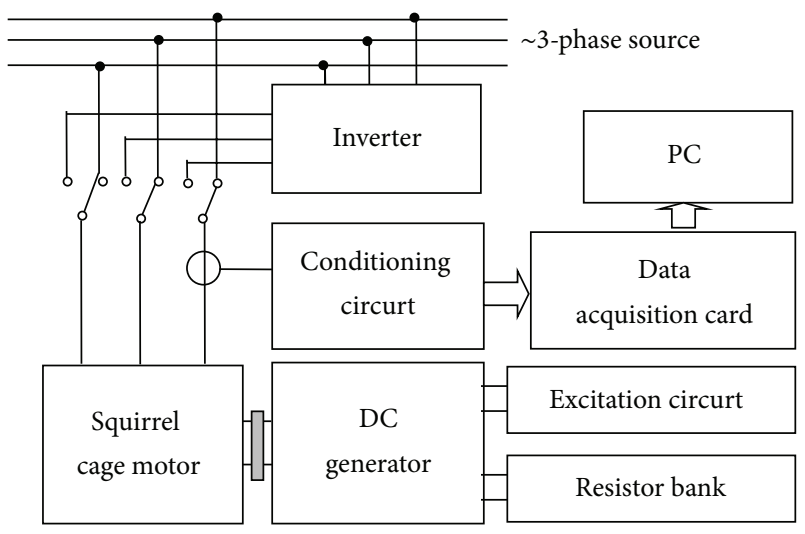

FIGURE 4: Schematic diagram of the experiment.

resistance and/or regulating the excitation current of the generator by relevant variable resistor. The resistance of this variable-resistor bank can be selected step by step by a selector on the bank. In the operating motor, a suitable position of the selector is selected and consequently the induction motor is loaded. By regulating the output voltage of the generator inserted in the excitation current path, the load level is regulated precisely.

(6) Induction-motor drive system type Simens440 with rating values in accordance with that of the SCIM: this drive has been mainly designed and built for openloop scalar controller in constant voltage/frequency $(\mathrm{CV} / f)$ method.

(7) Three-phase change-over switch to exchange the motor connections from the mains for the drive output.

(8) Signal conditioning circuits: since the used DAQ card accepts only voltage signals with maximum amplitudes of $\pm 10 \mathrm{~V}$, the type and amplitude of the signals are prepared before connection to the card. At the first stage, TBC300LTP Hall-effect current transformer is used to prepare the current signal and isolate it from the power circuit. Secondary side current is then converted to proportional voltage signals by current shunts. Then, all signals are transmitted to the DAQ card using a special shielded cable.

(9) PC equipped with a self-made data acquisition card for sampling the electrical data at a certain adjustable frequency and storing them in the memory.

Experiment setup to collect motor data and broken rotor used in the tests are illustrated in Figure 5.

4.2. Signal Acquisition Requirements. The experiments involved collecting the phase-a stator current and speed data of the induction motor for different load conditions and different excitation frequencies of $20 \mathrm{~Hz}, 32 \mathrm{~Hz}, 40 \mathrm{~Hz}$ and $50 \mathrm{~Hz}$, with three broken-rotor-bar fault and without any fault. The load conditions of the motor are $25 \%$, $50 \%, 75 \%$, and $94 \%$ full load, respectively. These load
TABLE 2: Induction motor technical data.

\begin{tabular}{lcc}
\hline Parameter & Value & Unit \\
\hline Nominal power & 3.0 & $\mathrm{~kW}$ \\
Nominal voltage & 380 & $\mathrm{~V}$ \\
Nominal current & 6.8 & $\mathrm{~A}$ \\
Nominal frequency & 50 & $\mathrm{~Hz}$ \\
Connection & $\Delta$ & \\
Number of poles & 4 & \\
Rotor slots number & 28 & \\
\hline
\end{tabular}

condition percentages are determined according to the motor nameplate information given in Table 2 .

Signal over-sampling method has been chosen in order to avoid aliasing. The stator current of motor was sampled with a frequency of $2 \mathrm{kHz}$ for main-fed and $40 \mathrm{kHz}$ for inverter-fed case. In the inverter-fed case, software filters have been implemented in order to avoid aliasing. More specifically, an 8-order anti-aliasing digital butter-worth filter was implemented and resampling of the signal has been done at $2 \mathrm{kHz}$. In our case, thirty seconds long data is acquired from all two motors for each load condition at each frequency mentioned above. Thus, the analyzed frequencies vary from 0 to $1 \mathrm{kHz}$ with a resolution of $0.03 \mathrm{~Hz}$. For the feature extraction and discriminant analysis, starting with the first sample, the acquired data is processed with a sliding window size of 30,000 samples at a slide amount of 10,000, resulting in 60 different data sets all together.

Figure 6 illustrates the intercept parts of $50 \mathrm{~Hz}$ stator current signal from the (a) main-fed and (b) inverterfed healthy squirrel-cage motors. An expert inspection of these waveforms reveals that the inverter-fed motor current waveform is heavily contaminated by the noise-like additive waveform due to PWM switching of the voltage source inverter. If we were to use this motor current waveform data to extract necessary features for fault detection and classification, we need to preprocess the data.

\section{Experimental Results}

5.1. Experiment 1. A nominally healthy squirrel-cage motor was firstly tested and the power spectrum of the stator current centered on the fundamental component supplied by (a) main and (b) inverter is shown in Figure 7. The results confirm that the motor rotor is healthy since the sidebands $f_{b}$ are not present. Comparisons of Figures 7(a) and 7(b) shows that a large amount of harmonic components is included in Figure 7(b) and the inverter supply does affect the spectrumidentifiability. Figure 8 indicates power spectrum of the stator current around the fundamental component for (a) mainfed and (b) inverter-fed fault squirrel-cage motors with three broken bars and full load. The annotations appearing in the figure denote the main sideband components around the supply frequency and corresponding amplitudes. Comparison of Figures 7 and 8 indicates that sideband components appear, which demonstrates the broken bars occurred. Although more frequency information appears, one could still identify 


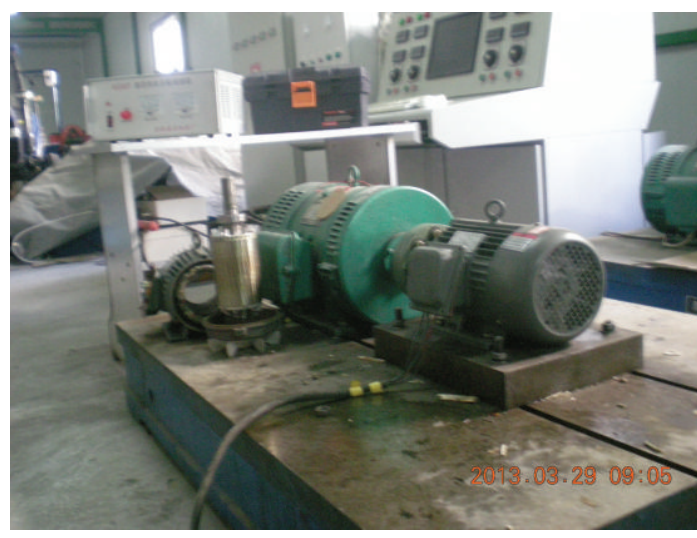

(a)

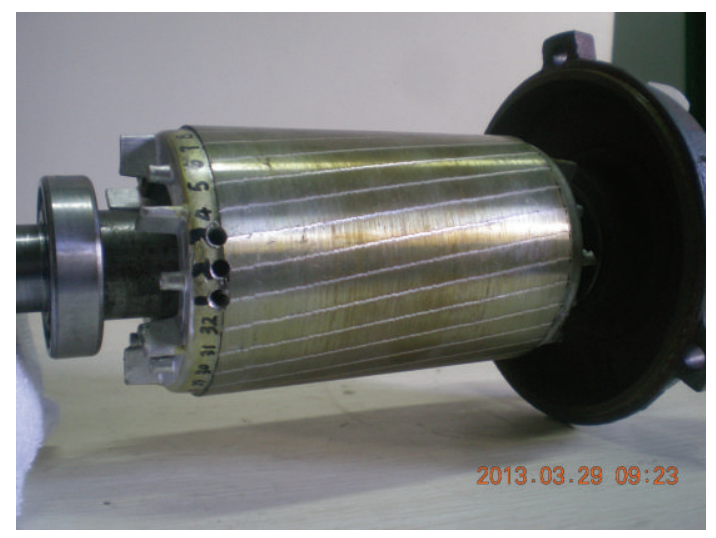

(b)

FIGURE 5: Experiment setup to collect motor data and broken rotor used in the tests.

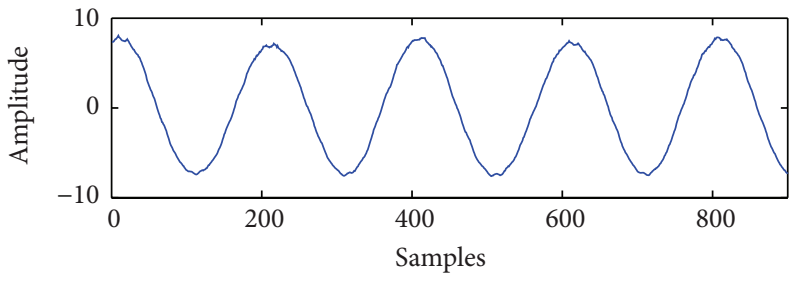

(a)

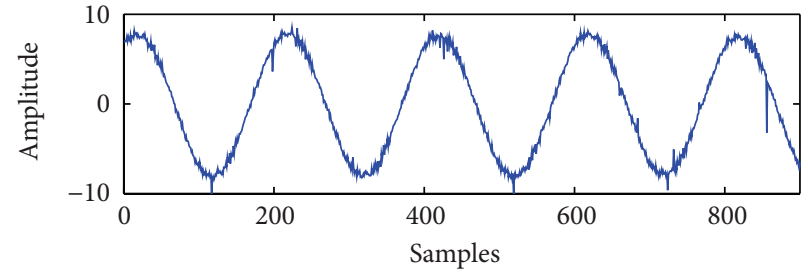

(b)

FIGURE 6: $50 \mathrm{~Hz}$ stator current signal from the (a) main-fed and (b) inverter-fed healthy squirrel-cage motor.

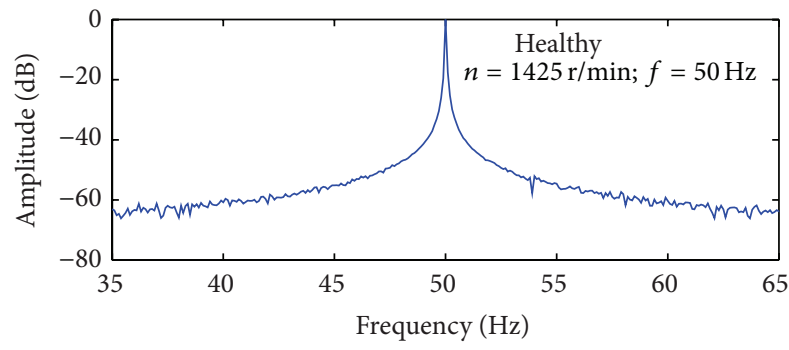

(a)

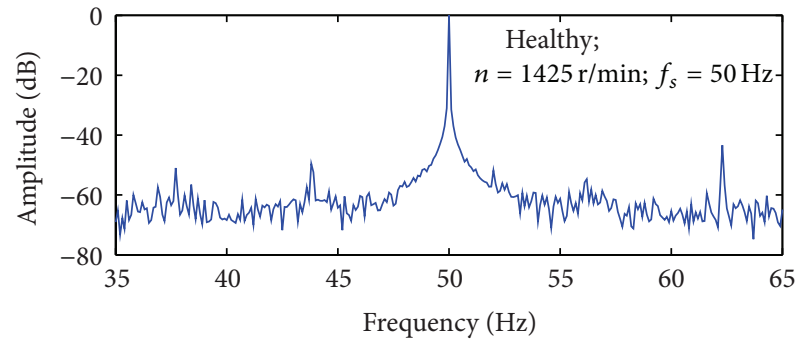

(b)

FIGURE 7: Power spectrum of the stator current around the fundamental component for (a) main-fed and (b) inverter-fed healthy squirrel-cage motor.

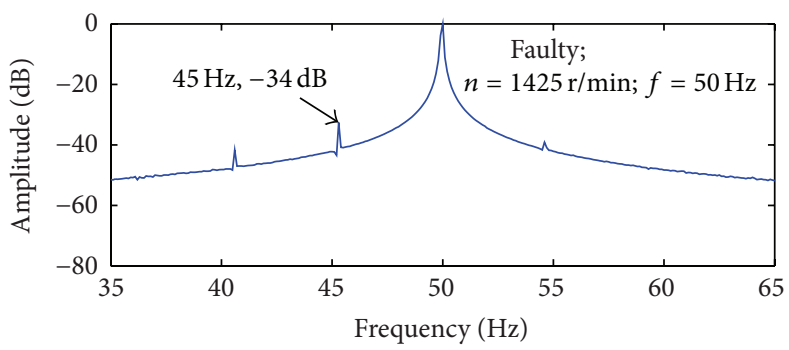

(a)

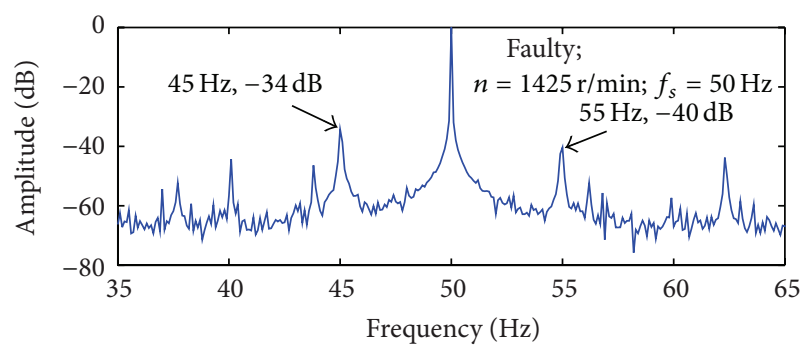

(b)

FIGURE 8: Power spectrum of the stator current around the fundamental component for (a) main-fed and (b) inverter-fed fault squirrel-cage motor. 


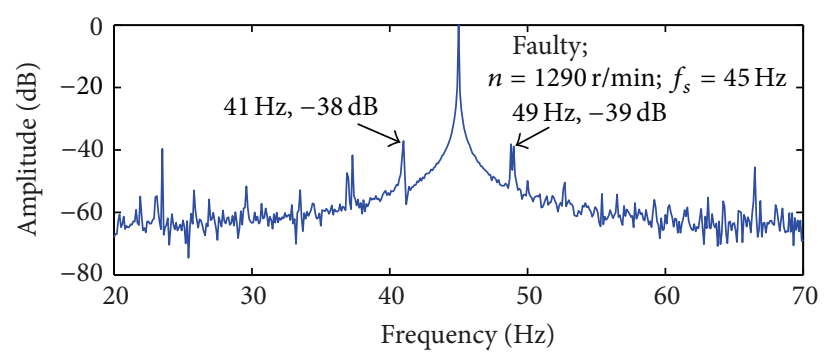

(a)

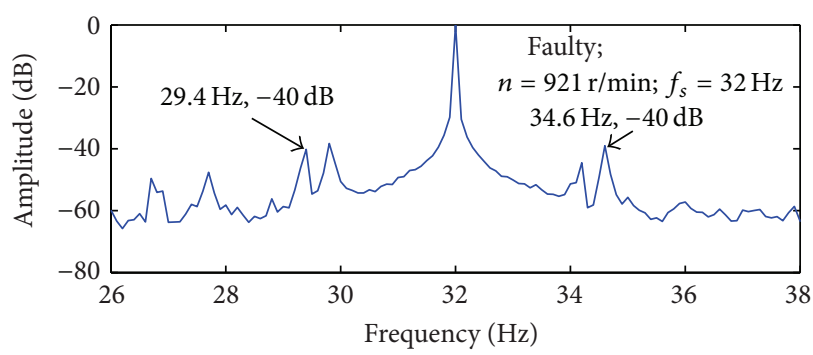

(c)

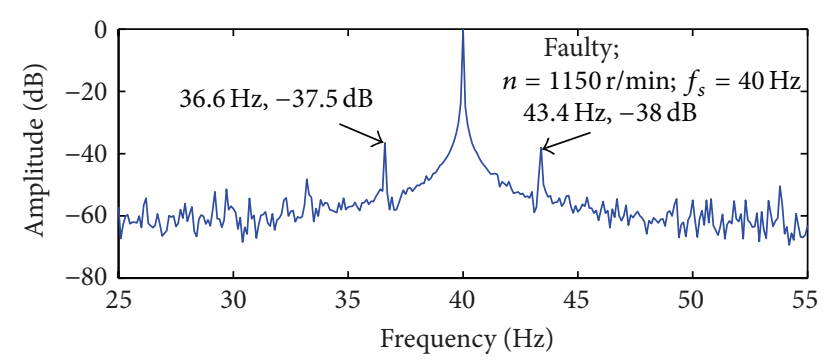

(b)

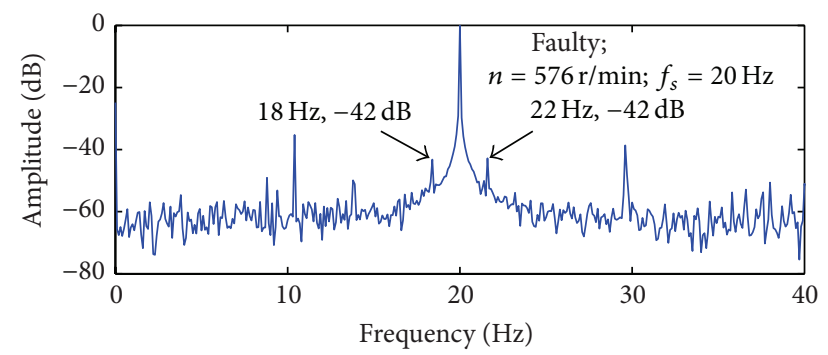

(d)

FIgURE 9: Power spectrum of the stator current around different excitation frequency of (a) $45 \mathrm{~Hz}$, (b) $40 \mathrm{~Hz}$, (c) $32 \mathrm{~Hz}$, and (d) $20 \mathrm{~Hz}$.

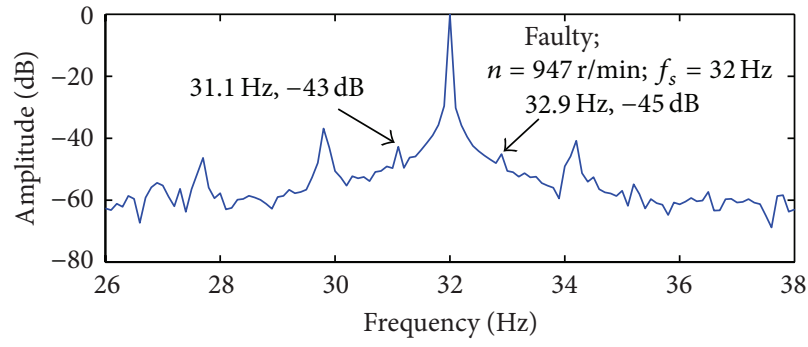

(a)

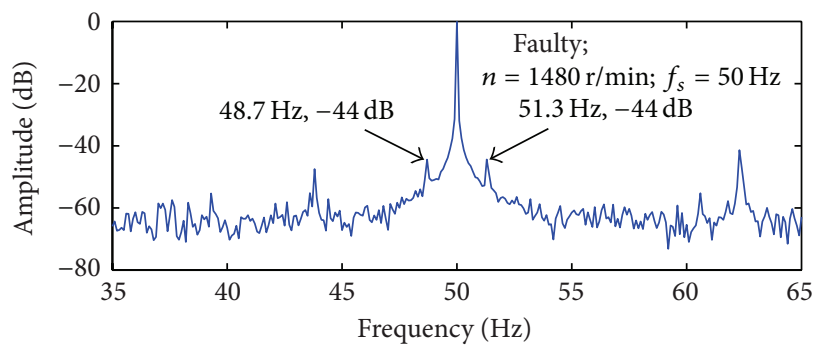

(c)

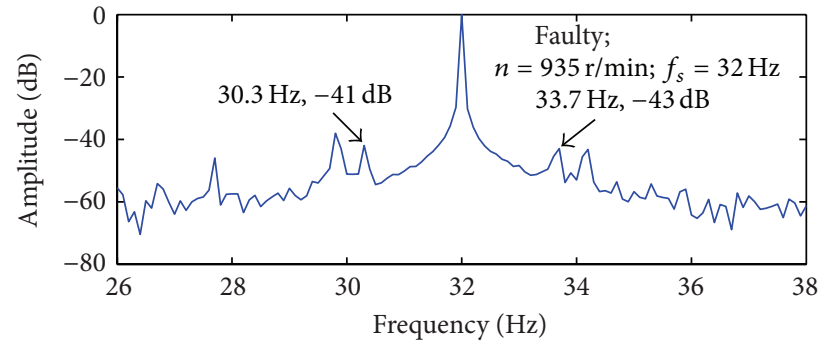

(b)

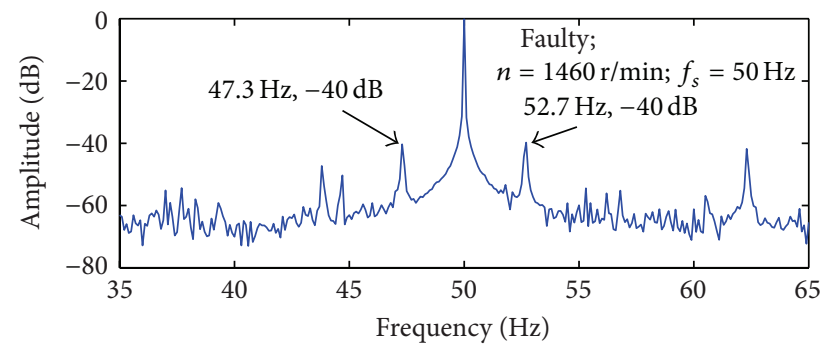

(d)

Figure 10: Power spectrum of the stator current around (left) $25 \%$ and (right) $50 \%$ full loads. Top row: $32 \mathrm{~Hz}$ and bottom row: $50 \mathrm{~Hz}$ reference frequency.

in Figure 8(b) broken rotor bars harmonics at $45 \mathrm{~Hz}$ and $55 \mathrm{~Hz}$ using our proposed method. Comparison of Figures $8(\mathrm{a})$ and 8 (b) also indicates that, for the same level of damage at the same load, the spectrum sidebands have the same amplitude for different supply.

5.2. Experiment 2. The second experiment involved fault squirrel-cage motor operating at different excitation frequency of inverter with three broken basr and full load.
Figure 9 gives the power spectrum of the stator current around the excitation frequencies of $45 \mathrm{~Hz}, 40 \mathrm{~Hz}, 32 \mathrm{~Hz}$, and $20 \mathrm{~Hz}$. As expected, the sideband components $f_{b}=(1 \pm 2 s) f_{s}$, depending on excitation frequency and load are present. Comparison of Figures 9(a), 9(b), 9(c), and 9(d) indicates that the left sideband harmonic component $(1-2 s) f_{s}$ varies from $(41 \mathrm{~Hz},-36 \mathrm{~dB})$ to $(18 \mathrm{~Hz},-42 \mathrm{~dB})$ and right harmonic $(1+$ $2 s) f_{s}$ from $(49 \mathrm{~Hz},-39 \mathrm{~dB})$ to $(22 \mathrm{~Hz},-42 \mathrm{~dB})$, when excitation frequency varies from $45 \mathrm{~Hz}$ to $20 \mathrm{~Hz}$. An expert inspection of 
these spectrums reveals that $f_{b}=(1 \pm 2 s) f_{s}$ are always located around the excitation frequency and the distance from the excitation frequency is $2 s f_{s}$. It also can be seen from Figure 9 that the amplitude of left sideband harmonic component (1 $2 s) f_{s}$ decreases with the excitation frequency, which is the result that when excitation frequency decreases the output voltage becomes lower and much smaller current is drawn by motor.

5.3. Experiment 3. In Experiment 3, additional experiments were performed with the faulty motor at different excitation frequencies $(32 \mathrm{~Hz}, 50 \mathrm{~Hz})$ under two different loads $(25 \%$, $50 \%$ ) to assess the performance of the proposed method over the full range of motor loads. Using the proposed diagnosis method, the collected phase current data of the fault motor with three broken bars were analyzed. Figures 10(a) and 10(b) show the results with $32 \mathrm{~Hz}$ excitation frequency at different loads and it can be seen that the fault characteristic frequency of broken rotor bars is exposed clearly. With the increase of load, the components of characteristic frequency become more and more significant, such as in Figure 10(a) of 25\% load and Figure 10(b) of 50\% load. The similar results could be received for fault motor with $50 \mathrm{~Hz}$ excitation frequency at different loads; see Figure 10(c) of 25\% load and Figure 10(d) of $50 \%$ load.

\section{Conclusion}

Open-loop voltage-source-inverter-fed squirrel-cage motors with constant voltage/frequency control method are widely used to drive fans, pumps, or other mechanisms involving speed control for energy-saving purpose. In these cases, the motor operates steadily with different excitation frequencies. Unlike the utility-driven case, the position of the current harmonics appearing on the stator-current spectrum due to broken rotor bar faults is highly dependent on the mechanical motor load and excitation frequency, which affects the slip frequency. As a consequence, the reliable identification and isolation of faults remains an open issue.

In this paper, a simplified fault current signal model is firstly established using switching function concept and frequency modulation theory. It is demonstrated that the inverter-fed motor current is heavily contaminated due to PWM switching of the voltage source inverter. However, the broken rotor bars fault characteristic frequency $f_{b}=$ $(1 \pm 2 s) f_{s}$, depending on faulty severity, loads, and excitation frequency, is always located around the excitation frequency and the distance from the excitation frequency is $2 s f_{s}$. Novel broken rotor bar fault diagnosis techniques using motor current signature analysis (MCSA) for open-loop voltagesource-inverter-fed squirrel-cage induction motors with constant voltage/frequency control method are subsequently proposed. Experimental results obtained on self-made $3 \mathrm{~kW}$ three-phase squirrel-cage induction motors are discussed. It is shown that experimental and simulation results are consistent with those of the model revealed and the proposed techniques are effective and accurate.
The method described works well under constant load torque, but some difficulties appear with regard to closedloop control-operated machines, when $f_{s}$ and $s$ vary almost simultaneously and it is impossible to employ the proposed method to diagnose broken rotor bar fault. At the moment, further research is carried out for the features, advantages, limitations, and improvements of the proposed techniques.

\section{Acknowledgment}

This work was supported by the Chinese academy of Sciences Key Deployment Project under Grant no. KGZD-EW-302.

\section{References}

[1] M. E. H. Benbouzid and G. B. Kliman, "What stator current processing-based technique to use for induction motor rotor faults diagnosis?" IEEE Transactions on Energy Conversion, vol. 18, no. 2, pp. 238-244, 2003.

[2] J. Cusido, L. Romeral, J. A. Ortega, J. A. Rosero, and A. G. Espinosa, "Fault detection in induction machines using power spectral density in wavelet decomposition," IEEE Transactions on Industrial Electronics, vol. 55, no. 2, pp. 633-643, 2008.

[3] T. M. Wolbank, P. Nussbaumer, H. Chen, and P. E. Macheiner, "Monitoring of rotor-bar defects in inverter-fed induction machines at zero load and speed," IEEE Transactions on Industrial Electronics, vol. 58, no. 5, pp. 1468-1478, 2011.

[4] A. Bellini, F. Filippetti, C. Tassoni, and G. A. Capolino, "Advances in diagnostic techniques for induction machines," IEEE Transactions on Industrial Electronics, vol. 55, no. 12, pp. 4109-4126, 2008.

[5] A. H. Bonnett and C. Yung, "Increased efficiency versus increased reliability," IEEE Industry Applications Magazine, vol. 14, no. 1, pp. 29-36, 2008.

[6] J. Cusido, L. Romeral, J. A. Ortega, A. Garcia, and J. R. Riba, "Wavelet and PDD as fault detection techniques," Electric Power Systems Research, vol. 80, no. 8, pp. 915-924, 2010.

[7] I. Culbert and W. Rhodes, "Using current signature analysis technology to reliably detect cage winding defects in squirrel cage induction motors," in Proceedings of the 52nd Annual Petroleum and Chemical Industry Conference, pp. 95101, September 2005.

[8] J. H. Jung, J. J. Lee, and B. H. Kwon, "Online diagnosis of induction motors using MCSA," IEEE Transactions on Industrial Electronics, vol. 53, no. 6, pp. 1842-1852, 2006.

[9] S. H. Kia, H. Henao, and G. A. Capolino, "A high-resolution frequency estimation method for three-phase induction machine fault detection," IEEE Transactions on Industrial Electronics, vol. 54, no. 4, pp. 2305-2314, 2007.

[10] D. Matic, F. Kulić, M. Pineda-Sánchez, and I. Kamenko, "Support vector machine classifier for diagnosis in electrical machines: application to broken bar," Expert Systems with Applications, vol. 39, no. 10, pp. 8681-8689, 2012.

[11] M. E. H. Benbouzid, "A review of induction motors signature analysis as a medium for faults detection," IEEE Transactions on Industrial Electronics, vol. 47, no. 5, pp. 984-993, 2000.

[12] M. F. Cabanas, F. Pedrayes, M. G. Melero et al., "Unambiguous detection of broken bars in asynchronous motors by means of a flux measurement-based procedure," IEEE Transactions on Instrumentation and Measurement, vol. 60, no. 3, pp. 891-899, 2011. 
[13] R. A. Gupta, A. K. Wadhwani, and S. R. Kapoor, "Early estimation of faults in induction motors using symbolic dynamicbased analysis of stator current samples," IEEE Transactions on Energy Conversion, vol. 26, no. 1, pp. 102-114, 2011.

[14] W. T. Thomson and M. Fenger, "Case histories of current signature analysis to detect faults in induction motor drives," in Proceedings of the IEEE International Electric Machines and Drives Conference (IEMDC '03), 2003.

[15] S. Choi, B. Akin, M. M. Rahimian, and H. A. Toliyat, "Implementation of a fault-diagnosis algorithm for induction machines based on advanced digital-signal-processing techniques," IEEE Transactions on Industrial Electronics, vol. 58, no. 3, pp. 937-948, 2011.

[16] B. Akin, S. B. Ozturk, H. A. Toliyat, and M. Rayner, "DSPbased sensorless electric motor fault diagnosis tools for electric and hybrid electric vehicle powertrain applications," IEEE Transactions on Vehicular Technology, vol. 58, no. 5, pp. 21502159, 2009.

[17] A. Bellini, "Closed-loop control impact on the diagnosis of induction motors faults," IEEE Transactions on Industry Applications, vol. 36, no. 5, pp. 1318-1329, 2000.

[18] S. M. A. Cruz and A. J. M. Cardoso, "Diagnosis of rotor faults in closed-loop induction motor drives," in Proceedings of the IEEE 41st IAS Annual Meeting on Industry Applications, pp. 23462353, October 2006.

[19] B. K. Lee and M. Ehsani, "A simplified functional simulation model for three-phase voltage-source inverter using switching function concept," IEEE Transactions on Industrial Electronics, vol. 48, no. 2, pp. 309-321, 2001.

[20] G. W. Chang and S. K. Chen, "An analytical approach for characterizing harmonic and interharmonic currents generated by VSI-fed adjustable speed drives," IEEE Transactions on Power Delivery, vol. 20, no. 4, pp. 2585-2593, 2005.

[21] S. Nandi, H. A. Toliyat, and X. D. Li, "Condition monitoring and fault diagnosis of electrical motors-a review," IEEE Transactions on Energy Conversion, vol. 20, no. 4, pp. 719-729, 2005.

[22] M. Eltabach and A. Charara, "Comparative investigation of electric signal analyses methods for mechanical fault detection in induction motors," Electric Power Components and Systems, vol. 35, no. 10, pp. 1161-1180, 2007.

[23] M. Eltabach, J. Antoni, and M. Najjar, "Quantitative analysis of noninvasive diagnostic procedures for induction motor drives," Mechanical Systems and Signal Processing, vol. 21, no. 7, pp. 2838-2856, 2007.

[24] A. Yazidi, H. Henao, G. A. Capolino, M. Artioli, and F. Filippetti, "Improvement of frequency resolution for threephase induction machine fault diagnosis," in Proceedings of the IEEE 40th IAS Annual Meeting on Industry Applications, vol. 1, pp. 20-25, October 2005.

[25] I. P. Georgakopoulos, E. D. Mitronikas, and A. N. Safacas, "Detection of induction motor faults in inverter drives using inverter input current analysis," IEEE Transactions on Industrial Electronics, vol. 58, no. 9, pp. 4365-4373, 2011.

[26] A. V. Oppenheim, R. W. Schafer, and J. R. Buck, Discrete-Time Signal Processing, Tsinghua University Press, Beijing, China, 2nd edition, 2005.

[27] J. Faiz and B. M. Ebrahimi, "A new pattern for detecting broken rotor bars in induction motors during start-up," IEEE Transactions on Magnetics, vol. 44, no. 12, pp. 4673-4683, 2008.
[28] B. Ayhan, M. Y. Chow, and M. H. Song, "Multiple discriminant analysis and neural-network-based monolith and partition fault-detection schemes for broken rotor bar in induction motors," IEEE Transactions on Industrial Electronics, vol. 53, no. 4, pp. 1298-1308, 2006. 


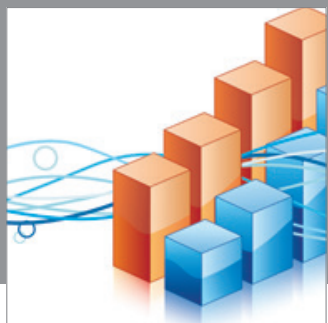

Advances in

Operations Research

mansans

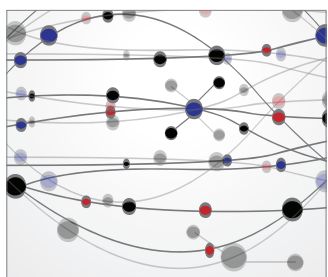

The Scientific World Journal
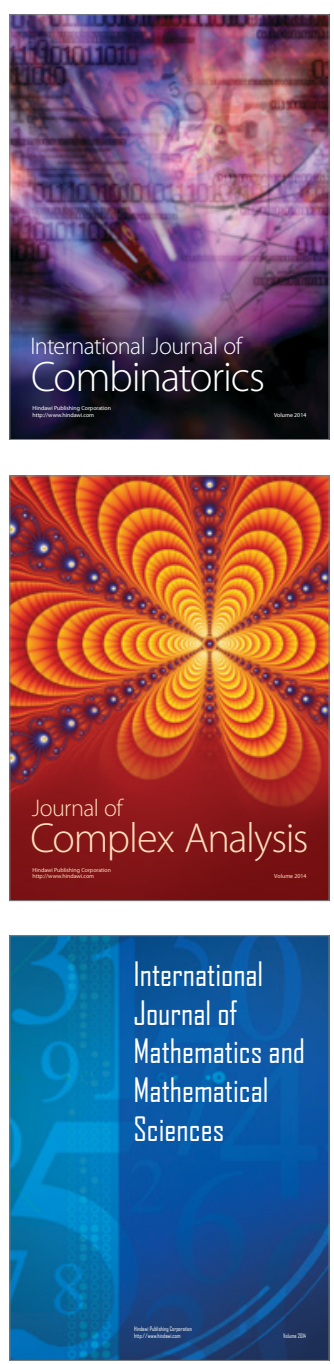
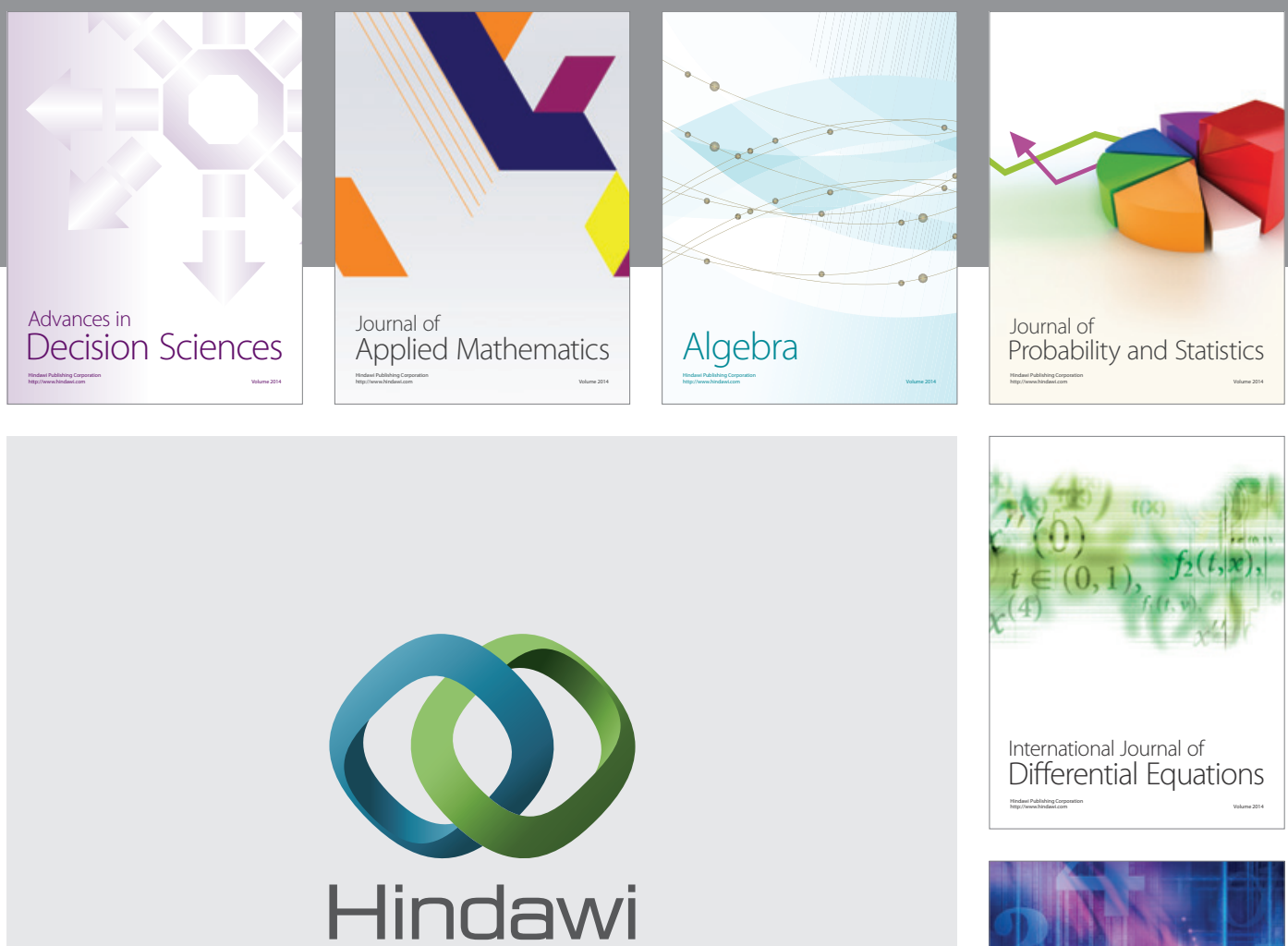

Submit your manuscripts at http://www.hindawi.com
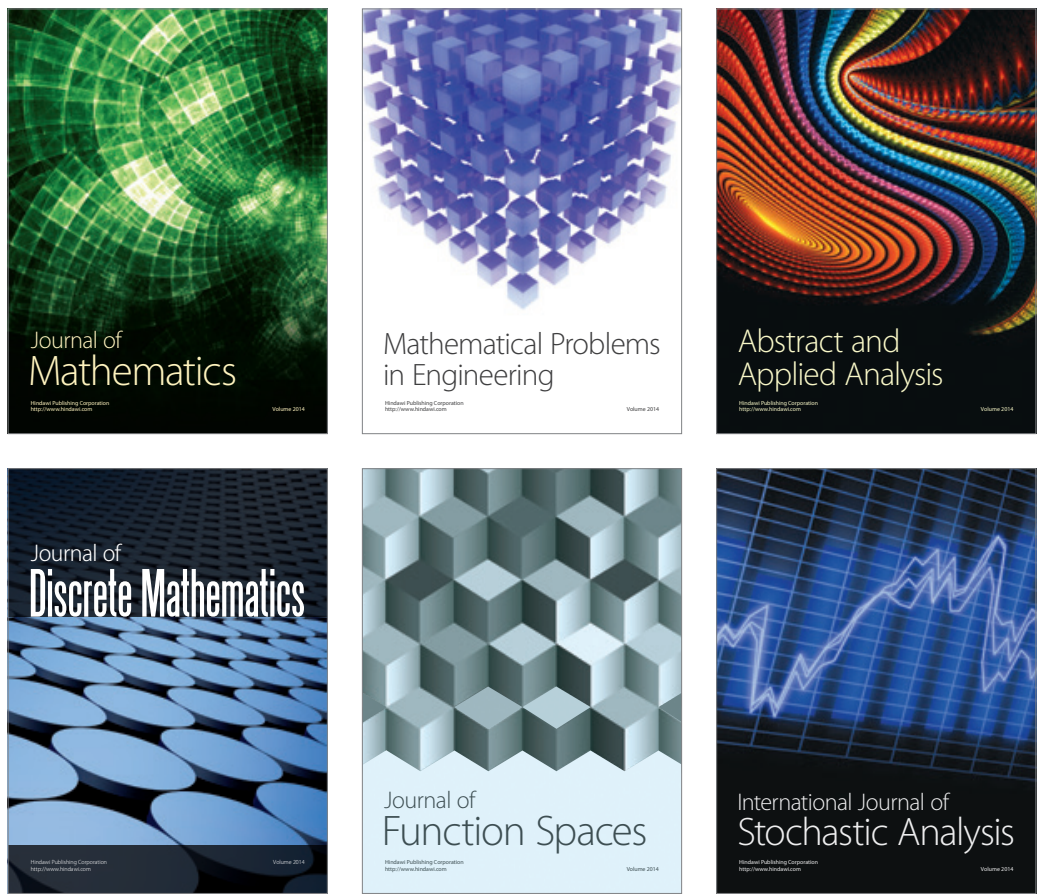

Journal of

Function Spaces

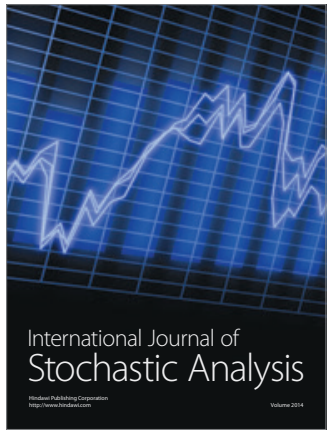

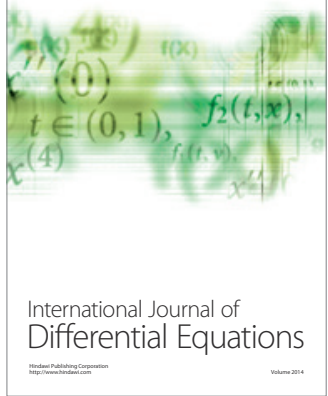
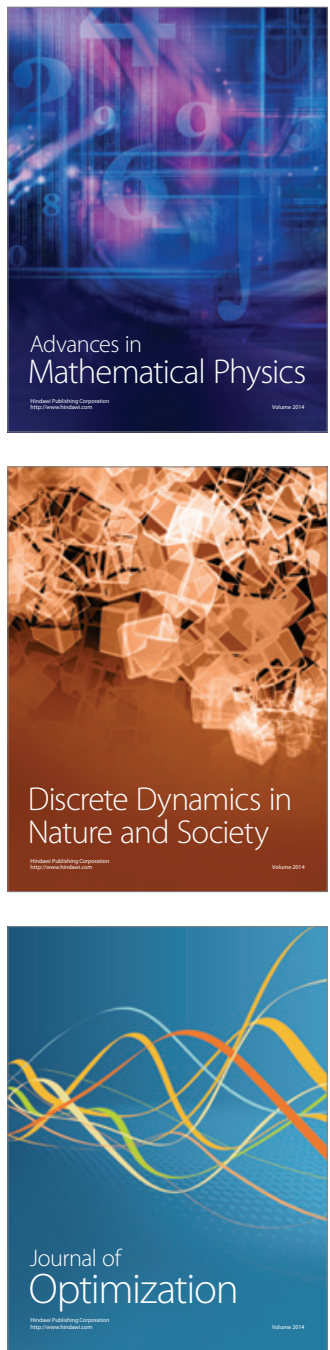